\title{
A EDUCAÇÃO NO PROJETO MISSIONÁRIO DO PROTESTANTISMO NO BRASIL
}

\author{
The education in the missionary project \\ of Protestantism in Brazil
}

\section{Carlos Eduardo B. Calvani}

Padre da Igreja Episcopal Anglicana do Brasil, Coordenador do Centro de Estudos Anglicanos, Doutor em Ciências da Religião pela UMESP, com especialização em Teologia e História, Londrina, PR - Brasil, e-mail: ccalvani@hotmail.com

\section{Resumo}

$\mathrm{O}$ artigo apresenta um panorama histórico das iniciativas educacionais ligadas às igrejas protestantes tradicionais. A partir da cosmovisão dos primeiros missionários protestantes norte-americanos, analisa o projeto educacional-evangelístico que norteava as primeiras escolas e colégios norte-americanos no Brasil. Por fim, pergunta sobre os motivos que levaram à estagnação desse projeto no Brasil identificando a origem dessas causas na progressiva influência do fundamentalismo evangélico norteamericano com sua visão estreita de evangelização como combate ao catolicismo, conversão de almas e um acentuado pré-milenismo, inibidor de qualquer iniciativa de projetos permanentes para a história.

Palavras-chave: Educação; Protestantismo brasileiro; História do protestantismo no Brasil; Missão protestante. 


\begin{abstract}
The article presents a historical view of the education initiatives related to the Protestant traditional churches. Since the first Protestant North American missionaries view, it analyses the education-evangelistc project what was orientating the first schools and North American colleges in Brazil. Finally, it asks on the motives that led to the stagnation of this project in Brazil identifying the origin of these causes in the progressive influence of the evangelic North American fundamentalism with his narrow vision of evangelization (combat to the Catholicism, conversion of souls and an accented pre-mileniarism) inhibiting of any initiative of constant projects for the history.

Keywords: Education; Brazilian Protestantism; History of protestantism in Brazil; Protestant mission.
\end{abstract}

\title{
Introdução
}

Este artigo tem um campo de delimitação muito preciso: as iniciativas educacionais (escolas e colégios) implantadas no Brasil por igrejas protestantes históricas. Não cabe aqui discorrer extensamente sobre a tipologia dos diversos tipos de protestantismo, pois esse assunto tornaria o texto extremamente longo. Para efeitos de clareza, consideramos "igrejas protestantes históricas" o conjunto de instituições religiosas que se instalaram no Brasil na segunda metade do século XIX como resultado do fervor missionário que tomou conta das igrejas protestantes norte-americanas da época.

A relação dessas igrejas com a reforma européia não é direta, mas indireta, posto que, boa parte delas não surgiu no século XVI, mas no século XVII (Igreja Presbiteriana, Igreja Batista, igrejas congregacionais) ou mesmo na transição do século XVII para o XVIII (Igreja Metodista). A Igreja Presbiteriana, a Batista e as congregacionais surgiram, enquanto instituições, após o fracasso da Revolução Puritana liderada por Oliver Cromwell, na Inglaterra. Com a restauração da monarquia e da Ecclesia Anglicana (Igreja da Inglaterra), esses grupos foram 
considerados "dissidentes", mas foi lhes permitido se organizar sob a forma de "igrejas-livres". A Confissão de Fé de Westminster (fórmula doutrinária aceita pelas igrejas presbiterianas é de 1643; a primeira confissão batista data de 1646; as igrejas congregacionais adotaram a Confissão de Westminster, mas se organizaram sob outra forma de governo por meio da declaração de Savoy sofre fé e ordem, de 1658). A Igreja Metodista, por sua vez, surgiu de um movimento interno da Igreja Anglicana, liderado pelo padre John Wesley, mas só foi organizada como corpo eclesiástico separado em 1795, quatro anos após a morte de Wesley (BETTENSON, 1967, p. 278-292).

$\mathrm{Na}$ Inglaterra, essas igrejas nunca experimentaram crescimento muito significativo. Foi nas colônias da América do Norte que elas realmente se consolidaram e ajudaram a criar uma nova sociedade e um novo país, impregnado dos ideais do protestantismo puritano e que, mesmo adotando o princípio republicano do estado laico, criaram o que, hoje, se chama "religião civil" norte-americana.

No Brasil, essas igrejas começaram a se instalar na segunda metade do século XIX e, nos estudos especializados, são hoje consideradas "protestantismo de missão" a fim de distingui-las dos primeiros grupos protestantes que se instalaram no Brasil no período entre 1810 e 1840 trazidas por imigrantes (capelanias anglicanas, luteranas e suíças). Atualmente, as Igrejas Presbiterianas, Batistas e Metodistas estão solidamente estabelecidas em todas as regiões do Brasil com escolas, colégios, faculdades e universidades que nasceram nos primeiros anos do trabalho missionário.

$\mathrm{O}$ primeiro missionário presbiteriano norte-americano chegou ao Brasil em 1859 e nos anos seguintes vieram outros. Os presbiterianos organizaram a 1. ${ }^{\text {a }}$ Igreja Presbiteriana do Rio de Janeiro, em 1863, e a 1. ${ }^{a}$ Igreja

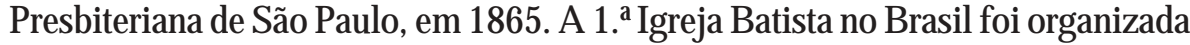
em 1871, contando apenas com norte-americanos sulistas que para cá vieram após o fim da guerra civil nos Estados Unidos. O trabalho, especificamente missionário, dos batistas no Brasil começou alguns anos mais tarde, em 1881. A Igreja Metodista dos Estados Unidos já havia enviado missionários ao Brasil em 1835, mas sem sucesso. Retornaram em 1869 e algum tempo depois organizaram suas primeiras igrejas no interior do estado de São Paulo.

As Igrejas Presbiterianas, Batistas e Metodistas sempre se caracterizaram, no início de suas atividades no Brasil, por uma forte preocupação educacional. Em pouco tempo, além de comunidades locais, 
começaram também a organizar escolas ou colégios. Algumas dessas instituições educacionais, hoje, são universidades enquanto outras permaneceram oferecendo apenas o ensino fundamental e médio. As principais instituições de ensino organizadas por presbiterianos e metodistas na fase de sua implantação no Brasil foram: Mackenzie College (São Paulo, 1870), ${ }^{1}$ Escola Evangélica de Botucatu-SP (1886); Piracicaba (1881), ${ }^{2}$ Escola Americana de Curitiba (1892), Colégio Internacional de Campinas (1893), Instituto Gammon (Lavras, MG, 1895), Colégio Americano de Natal-RS (1904), Colégio Americano de Pernambuco, hoje Colégio Agnes Erskine (1908), Escola Americana de Florianópolis (1906), Instituto Ponte Nova (Wagner, BA, 1906), Escola Evangélica Americana, em Varginha, MG (1921), Colégio Metodista Bennet (Rio de Janeiro, 1921), Colégio Dois de Julho (Salvador, BA, 1928). Entre os batistas as primeiras iniciativas são de 1888, quando foi inaugurada uma escola no Rio de Janeiro. Depois vieram outras em Salvador (1894), Campos (1896), Belo Horizonte (1898), Recife e São Paulo (1902), Vitória (1908), etc. Várias outras instituições foram abertas nos anos seguintes, mas com pouca estrutura e sem projetos pedagógicos bem definidos. Grande parte delas foi fechada nos anos 70 por não se adequarem às rigorosas exigências da Lei de Diretrizes e Bases da Educação de 1971.

Algumas dessas instituições nasciam com objetivos específicos como a educação feminina (Escola do Alto, no Rio de Janeiro (1892), o Colégio Americano Fluminense (1892), o Colégio Mineiro (1891) e o Colégio Americano de Petrópolis (1895), o Colégio Metodista de Ribeirão Preto (1899), o Colégio Isabela Hendrix, em Belo Horizonte (1904), o Colégio Metodista Bennett, no Rio de Janeiro (1921) e o Colégio Centenário de Santa Maria, no Rio Grande do Sul (1922)). Há um bom número de trabalhos acadêmicos na área de pedagogia e de história da educação no Brasil focalizados nessas iniciativas protestantes, discorrendo sobre a história de algumas dessas instituições.

Para os propósitos deste texto concentramo-nos na questão da articulação entre "evangelização" e "educação" enquanto duas faces do projeto missionário protestante no Brasil. Qual a motivação dos protestantes ao criar escolas? Qual era, enfim, a filosofia educacional que norteava essas iniciativas? Qual o "projeto pedagógico" e o perfil dos egressos? E, finalmente, por que

\footnotetext{
Atualmente é a Universidade Mackenzie, em São Paulo.
}

2 Hoje UNIMEP (Universidade Metodista de Piracicaba). 
essa preocupação educacional entre os protestantes diminuiu com o passar dos anos? Atualmente, não são muitas as redes de escolas e colégios protestantes pelo Brasil se comparadas às católicas. É certo que muitas igrejas protestantes continuam mantendo pequenas escolas e colégios em cidades do interior, mas o impacto que tem hoje na sociedade é pequeno, se comparado aos ideais dos primeiros missionários. Minha suspeita é a de que, durante o século XX, gradativamente, ganhou espaço entre os protestantes brasileiros a vertente mais conservadora da teologia protestante oriunda do sul dos Estados Unidos. Essa foi bem acolhida entre as lideranças protestantes conservadoras no Brasil e reforçada com a chegada do fundamentalismo protestante, que inibiu as iniciativas educacionais, concentrando as energias das igrejas quase que unicamente na evangelização conversionista e na polêmica com o catolicismo.

\section{Evangelização e educação no projeto missionário protestante para o Brasil}

Quando o protestantismo missionário chegou ao Brasil em meados do século XIX encontrou um campo social totalmente diferente do seu. Oriundos dos Estados Unidos, sociedade republicana, de matriz anglo-saxã e que defendia a separação total entre Igreja e Estado, aqui encontrou uma sociedade monárquica, de formação ibérica e com uma igreja estatal. O choque foi inevitável e seus desdobramentos já foram amplamente estudados no Brasil. Os protestantes, inicialmente, não podiam construir templos nem enterrar seus mortos nos cemitérios de então e tampouco tinham seu matrimônio reconhecido.

Os missionários que vieram do norte dos Estados Unidos partilhavam de um conceito de evangelização que incluía conscientemente a educação como estratégia para moldar, em longo prazo, uma nova sociedade, formando pessoas cujos valores fossem influenciados pela cultura anglo-saxã. Isso implicava na liberdade de consciência e religião, o livre comércio e os ideais de progresso da época. Em geral, esse grupo partilhava de uma teologia mais aberta às pesquisas e ao diálogo com a sociedade. Os que vieram do sul dos Estados Unidos (região hoje conhecida como "cinturão da Bíblia"), por sua vez, pendiam para linhas teológicas conservadoras que, anos mais tarde, se solidificaram no que hoje se chama "fundamentalismo". Na época, o sul dos Estados Unidos era considerado 
uma região "atrasada" do ponto de vista cultural e econômico, se comparada ao norte. Sempre foi a região que mais concentrava escravos e dos que lutaram contra a abolição da escravatura. O norte, por sua vez, era industrializado, burguês, abrigava várias universidades e altos índices de produtividade. Enquanto a economia do norte baseava-se nas indústrias, no comércio e nas demandas de uma emergente classe-média, a economia do sul estava amparada em grandes fazendas que dependiam da mão de obra escrava.

Os primeiros negros foram importados para a Virgínia pelo ano de 1621 [...] Daí ganhou terreno, pouco a pouco; mas, à medida que subia para 0 norte, o número dos escravos ia decrescendo; sempre se viram muito poucos negros na Nova Inglaterra. As colônias estavam fundadas; já transcorrera um século e um fato extraordinário começava a causar admiração a todos os olhares. As províncias que, por assim dizer, não tinham escravos, cresciam em população, em riqueza e em bem-estar, mais rapidamente do que as que os possuíam. Nas primeiras, entretanto, o habitante era obrigado a cultivar ele mesmo o solo, ou a alugar os serviços de outro; nas outras, tinha à sua disposição os trabalhadores cujos esforços não remuneravam. Havia, pois, trabalho e despesas, de um lado, ócio e economia do outro; no entanto, a economia ficava para os primeiros. (TOCQUEVILLE, 1977, p. 263-264).

O mesmo Tocqueville ao mencionar as diferenças entre a economia escravagista do sul e a economia industrializada do norte, toma as fronteiras do rio Ohio como ilustrativas dessa diferença:

O viajante que, situado no meio do Ohio, deixa-se arrastar pela corrente até a embocadura do rio no Mississipi, navega, pois, por assim dizer, entre a servidão e a liberdade, e tem apenas de lançar o olhar ao redor para julgar num instante qual é mais favorável à humanidade. À margem esquerda do rio, a população é dispersa; de tempos em tempos, percebese uma multidão de escravos a percorrer com ar inquieto campos semidesertos; a floresta primitiva reaparece constantemente; dissera-se que a sociedade está adormecida; o homem parece ocioso, a natureza oferece a imagem da atividade e da vida. Da margem direita, pelo contrario, elevase um rumor confuso que proclama ao longe a presença da indústria; ricas colheitas cobrem os campos; residências elegantes anunciam o gosto e os cuidados do lavrador; em toda parte, revela-se o conforto, o homem parece rico e contente, pois trabalha. O Estado do Kentucky foi fundado 
em 1775, o de Ohio só foi fundado doze anos depois; doze anos, na América, valem por mais de meio século na Europa. Hoje a população do Ohio já excede de 250.000 habitantes a do Kentucky. (TOCQUEVILLE, 1977, p. 264-265).

Tamanhas diferenças sócio-econômicas e culturais acabaram por levar nortistas e sulistas à guerra civil que terminou em 1865, com a vitória do norte e a abolição da escravatura. Porém, para muitos protestantes do sul, a escravidão era uma instituição ordenada diretamente por Deus e legitimada pelas Escrituras. Também se entendiam como os guardiães da pureza bíblica ou o "restante fiel" do povo do Pacto. Essas diferenças levaram todas as igrejas protestantes dos Estados Unidos a se dividirem. Surgiram então a Convenção Batista do Sul e a Convenção Batista do Norte, as Igrejas Presbiterianas do Sul e do Norte dos Estados Unidos e o mesmo aconteceu com a Igreja Metodista.

É bom lembrar que, por volta de 1870, aproximadamente, $10 \mathrm{mil}$ americanos abandonaram suas terras, sendo que cerca de dois mil vieram para o Brasil. Fundaram colônias nas províncias de Pará, Bahia, Espírito Santo, Rio de Janeiro, São Paulo e Paraná. A única colônia bem sucedida foi a que se estabeleceu em Santa Bárbara d'Oeste, entre Campinas e Limeira (SP). A partir de então, surge nas igrejas protestantes do sul dos Estados Unidos o interesse em enviar missionários para o Brasil. Até então, os missionários enviados provinham do norte. Foi assim que, em 1868, a Comissão das Missões Estrangeiras da Igreja Presbiteriana do Sul nomeou os pastores Edward Lane e George N. Morton para empreenderem uma missão entre os brasileiros. A Igreja Metodista do Sul enviou, em 1869, o Pastor Junius E. Newman para acompanhar os imigrantes metodistas.

Em Santa Bárbara d'Oeste organizou-se a 1. a Igreja Batista, em 1871. Esta igreja queria receber missionários por meio da Junta das Missões Estrangeiras da Convenção Batista do Sul. Mas, somente em 1880, a Junta resolveu iniciar uma atividade entre os brasileiros. Este impulso missionário foi motivado por um relatório do general sulista A. T. Hawthorne, que, em 1865, já tentara organizar uma colônia na Bahia. Foram enviados então os missionários William B. Bagby e Zacharias C. Taylor. Foi desta maneira que o protestantismo brasileiro foi reforçado por sulistas dos EUA, que defendiam as tradições feudais e o escravagismo. Quando a Convenção Batista do Sul debateu, em 1859, a possibilidade de iniciar uma missão 
brasileira, ficou registrada esta constatação: "o Brasil, como os Estados Unidos, tem escravos, e os missionários enviados pela Convenção não podem sentir-se constrangidos a combater a escravatura e assim envolver-se na política do país" (LÉONARD, 1963, p. 74-75).

No que se refere à educação, as diferenças entre norte e sul também eram consideráveis. Além das já mencionadas universidades, o norte possuía um bem-organizado sistema de escolas públicas gratuitas e alguns colégios particulares ligados a Igrejas. A educação ali estava voltada para a cidadania, a preparação profissional e religiosa. Além da alfabetização, considerada essencial para um povo que baseava sua fé na leitura da Bíblia, o sistema educacional do norte objetivava preparar os estudantes para desenvolver talentos necessários à indústria, ao comércio e às questões políticas da nação. Era uma educação essencialmente pragmática, que valorizava a livre-iniciativa, a formação técnica necessária para o funcionamento das indústrias que surgiam e a organização política destinada a dar sustentabilidade ao projeto de uma nação republicana que se entendia como a mais próxima realização dos ideais do Reino de Deus na terra.

Em contraste com o sistema educacional ainda precário do Brasil da época, esse modelo encontrou grande receptividade, como veremos, por parte de certas camadas da elite intelectual brasileira formada por republicanos, maçons, comerciantes e pequenos empresários que se espelhavam no crescimento econômico dos Estados Unidos e da Inglaterra como ideais para o Brasil.

De fato, desde meados de 1850, os Estados Unidos apresentavam altos índices de crescimento tecnológico que se intensificaram com o fim da guerra civil. Inovadoras tecnologias (para a época) surgiram exatamente nesse período, tais como as estradas de ferro e toda tecnologia do manuseio do ferro e aço, ${ }^{3}$ a mecanização da agricultura que gerava aumentos impressionantes na produção e expansão nas áreas de cultivo; o aperfeiçoamento da tecnologia do telefone abria um vasto campo de negócio na área das comunicações, reforçado pela invenção das máquinas de escrever, de registrar, de somar, dos linotipos, dos telégrafos diretamente ligados às bolsas de valores, etc. A eletricidade que, na década de 70, começou a ser usada timidamente como fonte de luz e energia, no final do século já era imprescindível aos bondes e outros aparelhos que encantavam os americanos e impressionavam as elites republicanas da América Latina.

Na virada do século, um terço das vias férreas do mundo encontrava-se nos territórios norteamericanos. 
Nesse quadro, não é difícil admirar porque uma parte da elite brasileira aproximou-se dos protestantes alinhando-se aos seus ideais. Afinal, esses representavam a promessa de que o Brasil poderia, em pouco tempo, assemelharse aos Estados Unidos no que se refere ao progresso tecnológico e educacional. A tão falada "aliança" entre protestantismo e maçonaria no Brasil, durante a segunda metade do século XIX, não aconteceu por afinidades religiosas, mas por interesses políticos e econômicos de ambas as partes. A maçonaria lutava pelo fim da monarquia, o estabelecimento da república, a abertura de mercado e, sem sombra de dúvida, todos os missionários protestantes desejavam o mesmo. Muitos deles eram maçons e grande parte dos brasileiros convertidos ao protestantismo, na época, também se filiaram às lojas. Nelas, além dos assuntos próprios de interesse da maçonaria, podiam-se estabelecer contatos, fazer amizades e discutir estratégias políticas para o futuro do Brasil.

Na cosmovisão dos missionários protestantes oriundos dos Estados Unidos, a criação de escolas e colégios era fundamental para conquistar espaço na sociedade brasileira. Além disso, tais educandários deveriam servir também como local de testemunho de uma religiosidade supostamente mais racional e menos supersticiosa, marcada por valores morais também supostamente superiores.

\section{$O$ ideal protestante de educação}

O problema da educação para os missionários tem um sentido mais totalizante: ultrapassa os limites de uma expressão evangélica, engloba-se em uma concepção de vida. Para a tradição do protestantismo americano, religião, democracia política, liberdade individual e responsabilidade são concebidas como parte de um todo, que está envolvido por uma inflexível fé na educação (RAMALHO, 1975, p. 79).

Em 1882, em carta aos Estados Unidos da América, o missionário batista William Bagby apresentou à igreja norte-americana um plano destacando o papel da educação como instrumento de evangelização:

Tais colégios prepararão o caminho para a marcha das igrejas [...] colégios fundados nestes princípios triunfarão sobre todo o inimigo e conquistarão a boa vontade até de nossos próprios adversários. Mandai missionários 
que estabeleçam colégios evangélicos, e o poder irresistível do Evangelho irá avante na América do Sul e a terra do Cruzeiro do Sul brilhará com a luz resplandecente do Reino de Cristo. (HACK, 2000, p. 62).

Tais palavras nos permitem compreender que, para muitos protestantes, a construção de colégios era parte integral do projeto de evangelização. Crabtree, importante historiador e líder batista no Brasil, resumiu o ideal de educação que sempre impulsionou os batistas, dizendo:

Não obstante o poder maravilhoso do Evangelho na transformação imediata dos ideais do indivíduo, a superioridade das doutrinas batistas não será demonstrada ao povo brasileiro exclusivamente no campo da evangelização. É, justamente, no campo da educação que o Evangelho produz os seus frutos seletos e superiores, homens preparados para falar com poder à consciência nacional. (CRABTREE, 1962, p. 125).

O mesmo sentimento também estava presente entre os presbiterianos. Paul Pierson, avaliando as atas da Missão Presbiteriana do Brasil, observa que ali estão contidos de forma explícita os alvos das instituições missionárias dessa denominação: auxiliar na propagação do evangelho, especialmente entre as classes superiores (grifo meu); preparar os crentes para viverem em um nível econômico mais elevado, o que lhes permitiria sustentar a igreja e exercer maior influência na sociedade; proporcionar um ambiente educacional de nível espiritual e moral mais elevado do que o encontrado nas escolas públicas e católicas; preparar líderes para a igreja; e contribuir de maneira geral para a cultura e o progresso da nação ensinando os alunos a usarem seus recursos de modo mais eficiente (MATOS, 1999, p. 64).

O sucesso que os colégios protestantes obtiveram no Brasil no final do século XIX e início do século XX explica-se pelo fato de que preencheram um vazio na cultura brasileira. A situação educacional no Brasil, desde a expulsão dos jesuítas, era de muita precariedade. Não havia bibliotecas públicas, universidades e o ensino primário era praticamente inexistente, fora dos grandes centros urbanos. A educação no Brasil-Império era privilégio de uma pequena elite ligada às oligarquias agrárias que ou enviava os filhos para estudar na Europa ou contratava professores/as estrangeiros que gozavam de muito prestígio junto à sociedade. Conforme Elias, as escolas públicas da época eram: 
Extremamente precárias, funcionavam em prédios adaptados e, muitas vezes, na residência do professor. As classes - com alunos de diferentes idades e graus de conhecimento e em número excessivo - eram atendidas por apenas um professor, em geral não habilitado a ministrar aulas. $\mathrm{O}$ currículo adotado não ia alem das primeiras letras, noções de gramática portuguesa, um pouco de aritmética, além de aulas avulsas de francês e latim. (ELIAS, 2005, p. 82).

A criação das escolas americanas protestantes no Brasil trouxe para a educação novas práticas. Dentre elas, a classe média, principalmente do sudeste do Brasil, começou a investir nas escolas, aceitando pagar mensalidades e investindo na educação de seus filhos. Além disso, as escolas e colégios protestantes trouxeram inovações como o princípio co-educativo, colocando meninos e meninas, rapazes e moças nas mesmas salas de aula. Isso atraiu a classe média emergente e imigrante que, localizados nas fazendas do interior paulista, não tinham acesso à educação pública. Porém, a mistura de sexos entre as crianças na mesma na sala (algo comum nos Estados Unidos) não era bem visto por famílias tradicionais que hesitavam em colocar suas filhas em educandários juntamente com rapazes, herança de uma moralidade herdada dos colonizadores portugueses.

Essa prática, hoje tão comum, despertou forte oposição nos círculos católicos. Em Lages, por exemplo, o padre Pires Martins qualificava o ensino oferecido pela Escola Americana (Presbiteriana) de "educação promíscua" (TAPIA, 2007). No Rio Grande do Sul, o arcebispo Dom João Becker liderou, a partir de 1912, um movimento que advogava a identificação do povo brasileiro com a religião católico-romana e que denunciava toda infiltração norte-americana, especialmente a Associação Cristã de Moços, o Colégio Cruzeiro do Sul (educandário anglicano em Porto Alegre) e o Porto Alegre College (metodista).

A oposição católica se dava também por meio de cartas pastorais dos bispos. Em 1925, o bispo de Belo Horizonte, Dom Antônio dos Santos Cabral, exortou os católicos através de Carta Pastoral, a jurarem jamais confiar a educação de seus filhos a colégios protestantes. Discurso semelhante encontrase na Carta Pastoral de Dom Silvério Gomes Pimenta:

Já outras vezes temos despertado a atenção dos fiéis para o perigo em que precipitão seus filhos confiando-os a escolas acatholicas, mestres hereges, ímpios, escandalosos, ou infames por factos conhecidos; e 
sabemos que nossos cooperadores não se tem descuidado, nem se descuidarão, de resguardar suas ovelhas neste arriscado perigo [...] Há muito trabalhão os methodistas, e outras seitas da América do Norte, por attrahir e arrastar os Brasileiros; mas suas indústrias e esforços estacarão deante da resistência de nosso povo fiel. Por isso brademos aos Paes, com todas as forças d'alma,que por nenhuma razão, por nenhuma conveniência, por nenhuma solicitação de amigos confiem seus filhos ou pupilos a collegios protestantes, nem a mestres ímpios, ou de maos costumes. Cousa triste é a ignorância; muito mais triste porem é o erro em pontos de religião. O ignorante, mas crente e virtuoso, se salva; o instruído em sciencias humanas, mas sem a fé verdadeira, perder-se-á eternamente. (PIMENTA, 1921).

Além do princípio co-educativo, os métodos pedagógicos protestantes também eram copiados do modelo norte-americano. Em São Paulo, a escola idealizada pelo casal Chamberlain, e que mais tarde tornou-se o Instituto Mackenzie, introduziu o método intuitivo e a leitura silenciosa, diferentemente do que faziam as escolas brasileiras com seu costume de leitura em voz alta e decoração sem raciocínio. Além disso, seguindo as tradições do pragmatismo norte-americano, davam grande ênfase ao treinamento manual, à ginástica e aos esportes em geral. Talvez porque, na época, eram vítimas de muito preconceito, os protestantes do Mackenzie não admitiam manifestações de preconceito de qualquer espécie, fossem de raça, sexo, político ou de orientação religiosa. De acordo com os princípios éticos e democráticos norteamericanos, consideravam que, sendo a educação um direito do indivíduo, existia também a obrigação de garanti-la indistintamente a todos, independentemente da raça, da cor, do sexo ou da classe social. Desse modo, a propaganda educativa dos protestantes investia num discurso que ia ao encontro dos ideais da classe média emergente, pois anunciava que os colégios eram abertos para formar uma nova elite para a república, semelhante à de seu país de origem. O ensino enfatizava o individualismo ético incutindo valores como honra, virtude, respeito mútuo, liberdade, solidariedade e cidadania, o que caia no agrade de intelectuais republicados da época e formadores de opinião que, mesmo sem nunca terem aderido ao protestantismo, viam com bons olhos essas iniciativas, tais como Rui Barbosa, Rangel Pestana, Caetano de Campos, Prudente de Moraes, etc. Dentre as inovações introduzidas pelos colégios protestantes no Brasil, Barbanti destaca: 
Mesas, bancos de assentos reversíveis, pedras de ardósia, mapas, globos, ábacos, mapas de anatomia (olho, coração), modelo de cabeça, retratos de homens ilustres, microscópios, aparelhos de física e química, aparelhos para ginástica, aparelho telegráfico, pequeno prelo e caixa com 64 formas e sólidos para o ensino objetivo. (BARBANTI, 1981, p. 149; AZEVEDO, 1958, p. 601).

O famoso educador Fernando de Azevedo, na 3. ${ }^{\text {a }}$ parte de sua obra $A$ Cultura Brasileira, interpreta a inserção da educação protestante no Brasil na transição entre os regimes monárquico e republicano, observando que "nenhum fermento novo se introduziu na massa do ensino, a não ser o que se preparava nos colégios leigos ou se formava, nos fins do Império, com o aparecimento das primeiras escolas protestantes, como a Escola Americana, fundada em 1870[...], "Mackenzie College", ou o Colégio Piracicabano (1881), para meninas, em São Paulo, e o Colégio Americano (1885), em Porto Alegre, [...] de iniciativa dos metodistas [...] (AZEVEDO, 1958, p. 601).

O discurso do protestantismo referente a evangelização e educação tinha um destinatário social específico: as elites emergentes. Esses propósitos coincidiam com os ideais das classes republicanas dos grandes centros urbanos da época. Ana Lúcia Cordeiro, comparando os projetos católicos e metodistas da época, diz:

\begin{abstract}
Alimentados pelas idéias de modernização e progresso e estando profundamente insatisfeitos com o atraso do país e com a má formação intelectual e moral das pessoas, intelectuais, políticos e grandes proprietários rurais viam a educação como um meio de transformação social, a chave para a solução de todos os problemas nacionais. A crença do poder redentor da educação pressupunha a confiança na instrução como um elemento formador, ou, como quer José Luis Novaes (2001), “conformador” dos indivíduos. Segundo esse autor, no referido período a educação foi atrelada à cidadania e, dessa forma, foi instituída a sua imprescindibilidade para a formação do cidadão. Articulada com a valorização da ciência e com os rudimentos de uma cultura letrada ela se apresentava como interpretação conciliadora capaz de explicar os motivos do atraso da sociedade brasileira e apontar a solução para o mesmo. (CORDEIRO, 2005, p. 174).
\end{abstract}

De fato, a educação foi o grande ideal das elites brasileiras nas últimas décadas do século XIX e nas primeiras décadas do século XX. O projeto educacional protestante procurou essa fresta para penetrar na sociedade 
brasileira. Esperavam também converter muitas famílias dessas elites para suas igrejas. Isso, porém, não aconteceu. As elites serviram-se das escolas protestantes, apoiaram suas iniciativas e alguns até mesmo incorporaram ideais do protestantismo norte-americano, porém, não foram muitos os que se converteram à nova fé, filiando-se às igrejas evangélicas.

O protestantismo brasileiro encontrou na classe média emergente e, sobretudo na maçonaria, um interlocutor co-beligerante com o qual partilhava ideais políticos (sistema republicano com estado laico), filosóficos (positivismo), econômicos (liberalismo) e religiosos (anti-clericalismo e anti-catolicismo). Muitos missionários batistas, metodistas e presbiterianos eram também maçons e essa aliança prosseguiu nos primeiros anos do século XX. Essa classe estava convencida de que o modelo de educação em vigor no Brasil não correspondia às suas expectativas e por isso apoiou a inserção do protestantismo norte-americano no Brasil de diversas maneiras. Alguns líderes da primeira república tinham laços íntimos com o protestantismo, tal como Prudente de Morais $\left(3 .^{\circ}\right.$ Presidente da República) que estudara em um colégio metodista em Piracicaba. Além disso, a cidade de Itu, no interior de São Paulo, tida na época como quartel-general republicano, situava-se em uma região com forte concentração protestante.

A afinidade entre os ideais dos primeiros missionários protestantes e a classe-média republicana brasileira era respaldada pela promessa de que os educandários protestantes pudessem introduzir alguma novidade na precariedade do sistema educacional brasileiro. Isso, de fato, acontecia, pois a prática protestante era baseada no método indutivo, ao contrário da educação católica e do estado, pautadas no método dedutivo e de memorização. Conforme Mesquida, "foi o método pedagógico [...], que tinha como característica principal levar a criança ao desenvolvimento de suas faculdades mentais por meio da observação, a grande atração dos colégios norte-americanos. ${ }^{4}$ A própria estrutura física onde se desenvolvia o processo educacional também era marcada pela diferença. Comentando sobre o Colégio Piracicabano (núcleo de onde se desenvolveu a UNIMEP), Elias aponta algumas características que o diferenciava dos demais educandários:

4 MESQUIDA, Peri. Hegemonia norte-americana e educação protestante no Brasil. Juiz de Fora: UFJF; Piracicaba: UNIMEP, 1994. 
Prédios próprios, com arquitetura que os distinguia pelas salas amplas e construídas especificamente para o ensino. As classes eram mistas. As carteiras de estudante passaram a serem individuais. Havia salas especiais para música, geografia, com imensa quantidade de mapas, cartazes com esqueleto do corpo humano, pesos e medidas para o ensino do sistema métrico, microscópios. E, já no colégio Piracicabano, as disciplinas eram latim, português, inglês, francês, gramática, caligrafia, aritmética, matemática, álgebra, geometria, astronomia, cosmografia, geografia, história universal, história do Brasil, história sagrada, literatura, botânica, física, química, zoologia, mineralogia, desenho, música, piano, costura, bordado e ginástica. (ELIAS, 2005, p. 82).

Peri Mesquida (1994, p. 48) observa ainda, que o Colégio Piracicabano, fundado em 1881, foi a célula-mater da reforma da instrução pública de São Paulo. Neste colégio, o então governador de São Paulo e mais tarde Presidente da República, Prudente de Moraes, pôde avaliar a prática da pedagogia moderna importada dos Estados Unidos e adaptá-la ao sistema educacional daquele estado.

\section{Desvios de rota}

Quando, na segunda década do século XX, as igrejas protestantes brasileiras começaram a conseguir sua autonomia financeira e independência política em relação às matrizes norte-americanas, a ênfase na abertura de colégios diminuiu bastante em relação às décadas anteriores. Isso se deve a dois motivos: a) conflitos internos entre as primeiras gerações de líderes protestantes brasileiros que várias vezes se envolviam em conflitos pelo poder nas cúpulas eclesiásticas e nos colégios e b) a penetração inicialmente sutil e posteriormente avassaladora do fundamentalismo norte-americano. Em meados do século XX, o fundamentalismo passou a ser a teologia mais influente nas igrejas protestantes, especialmente entre os pastores que ocupavam cargos de liderança. Muitos seguiam a vertente do fundamentalismo que espera, passivamente a segunda vinda corporal de Jesus Cristo à terra e que não vislumbra qualquer possibilidade ou mesmo necessidade de melhoria na sociedade, pois essa está destinada ao juízo. Tal teologia inibe as iniciativas sociais e educacionais e focaliza a missão da igreja apenas no anúncio do evangelho. 
À medida que as igrejas protestantes foram se tornando independentes, os missionários começaram a perder peso político. Muitos dos brasileiros convertidos ao protestantismo e posteriormente ordenados pastores, não acreditavam na eficácia dos programas educacionais como fatores de evangelização indireta e desejavam que o investimento maior e principal da igreja fosse no proselitismo direto. Não foram poucas as crises políticas nas igrejas protestantes envolvendo missionários que desejavam maior investimento na educação e líderes brasileiros que reclamavam que os lucros financeiros alcançados pelos colégios, ao invés de utilizados para reinvestimento na educação, deveriam ser direcionados às frentes missionárias e à abertura de novas igrejas.

$\mathrm{O}$ crescimento da influência fundamentalista no protestantismo brasileiro, intensificada a partir dos anos 60 , foi muito nociva e prejudicial a essas igrejas. Poucas foram as escolas protestantes nascidas nos últimos 30 anos. Embora em várias cidades, igrejas evangélicas tenham tomado iniciativas para abertura de escolas de ensino fundamental, dificilmente essas se desenvolvem a ponto de alcançar condições para oferecer também ensino médio e superior. Nesse sentido, poderíamos dizer que a obra missionária protestante no Brasil perdeu muitos de seus primeiros ideais. Hoje em dia, a maioria das igrejas evangélicas e protestante entende a educação como um apêndice da missão ou uma força auxiliar, mas não como um elemento central, capaz de impregnar a sociedade com benefícios perenes.

\section{Referências}

AZEVEDO, F. de. A cultura brasileira. 3. ed. Rio de Janeiro: IBGE, 1958.

BARBANTI, M. L. H. Colégios americanos de confissão protestante na província de São Paulo: sua aceitação pelas elites progressistas da época. São Paulo: Didática, 1981.

BETTENSON, H. Documentos da igreja cristã. São Paulo: ASTE, 1967.

CORDEIRO, A. L. Religião e projetos educacionais para a nação: a disputa entre metodistas e católicos na primeira república brasileira. Horizonte, Belo Horizonte, v. 4, n. 7, p. 110-124, dez. 2005. 
CRABTREE, A. R. História dos batistas do Brasil. Rio de Janeiro: Casa Publicadora Batista, 1962.

ELIAS, B. V. Inovação americana na educação do Brasil. Nossa História, São Paulo, n. 23, p. 81-83, set. 2005.

HACK, O. H. Protestantismo e educação brasileira. 2. ed. São Paulo: Cultura Cristã, 2000.

LÉONARD, É. G. O protestantismo brasileiro: estudo de eclesiologia e história social. São Paulo: Aste, 1963.

MATOS, A. S. O colégio protestante de São Paulo: um estudo de caso sobre o lugar da educação na estratégia missionária da igreja. Fides Reformata, São Paulo, v. 4, n. 2, p. 1-25, jul./dez., 1999. Disponível em: <http://www.mackenzie.br/ fileadmin/Mantenedora/CPAJ/revista/VOLUME_IV_1999_2/Alderi.pdf >. Acesso em: 20 nov. 2007.

MESQUIDA, P. Hegemonia norte-americana e educação protestante no Brasil. Juiz de Fora: EDUFJF; São Bernardo do Campo: EDITEO, 1994.

PIMENTA, D. S. G. Carta pastoral: o perigo dos collegios acatholicos. Mariana: Typ. Archiepiscopal, 1921.

RAMALHO, J. P. Colégios protestantes no Brasil: uma interpretação sociológica da prática educativa dos colégios protestantes no Brasil no período de 1870 a 1940. Rio de Janeiro: Zahar, 1975.

TAPIA, J. E. Escola americana de Lages 1931-1942. 2007. Disponível em: $<\mathrm{w} w \mathrm{w}$. a n p u h.ue pg.br/Xxiiisimposio/anais/textos/ JOSÉ\%20ELIACHIM\%20BARROS\%20TAPIA.pdf >. Acesso em: 13 nov. 2007.

TOCQUEVILLE, A. A democracia na América. 2. ed. Belo Horizonte: Itatiaia; São Paulo: EDUSP, 1977.

Recebido: 10/02/2008

Received: 02/10/2008

Aprovado: 20/03/2008

Approved: 03/20/2008 